\title{
Religião e silenciamento do sofrimento: reflexões sobre morte e vida de mulheres em situação de violência*
}

\author{
Sandra Duarte de Souza
}

Universidade Metodista de São Paulo (Umesp)

\section{Resumo}

Os dados relativos à morte e adoecimento de mulheres no Brasil e no mundo diretamente relacionados à violência de gênero atestam que há um imenso contingente de mulheres que, por força dessa violência, têm suas vidas abreviadas. Muitas nunca contaram essa experiência de dor ou, ao contarem, foram "aconselhadas" a mantêla em segredo. A violência de gênero impõe às mulheres o silêncio sobre as suas dores. Seus sofrimentos são mantidos em segredo e guardados na casa, e a religião tem importante participação nisso, gerando a desmobilização da indignação contra a produção do sofrimento perpetrado contra as mulheres. O presente artigo objetiva tratar do silenciamento das mulheres em situação de violência como mecanismo de dificultação do comprometimento social com suas vidas, e toma o caso específico da menina de dez anos que foi violentada e engravidada pelo tio no Espírito Santo para orientar essa discussão.

Palavras-chave: Violência contra as mulheres; Silenciamento; Sofrimento; Religião.

\section{Religion and silencing of suffering: reflections on the death and life of women in situations of violence}

\begin{abstract}
Data related to the death and illness of women in Brazil and in the world directly related to gender-based violence attest that there is an immense contingent of women who, due to this violence, have their lives cut short. Many never reported this experience of pain or, when so, they have been "advised" to keep it a secret. Gender-based violence imposes on women silence about their pain. Their sufferings are kept a secret and are kept in
\end{abstract}

* O presente texto foi apresentado na mesa redonda "Perspectivas de Espiritualidade do Cuidado", com foco na violência contra as mulheres, no X Congresso Internacional em Ciências da Religião (X CICR) da PUC-Goiás. 
the house, and religion plays an important role in this, generating the demobilization of indignation against the production of suffering against women. This article aims to address the silencing of women in situations of violence as a mechanism to hinder social commitment to their lives, and uses the specific case of the ten-year-old girl who was raped and gotten pregnant by her uncle in Espírito Santo to guide this discussion. Keywords: violence against women; silencing; suffering; religion.

\section{Religión y silenciamiento del sufrimiento: reflexiones sobre la muerte y la vida de las mujeres en situaciones de violencia}

\section{Resumen}

Los datos sobre la muerte y enfermedad de las mujeres en Brasil y en el mundo directamente relacionados con la violencia de género atestiguan que hay un inmenso contingente de mujeres que, por la fuerza de esta violencia, tienen sus vidas abreviadas. Muchas nunca hablaron de esta experiencia de dolor o, cuando se lo contaron, se les "aconsejó" que la mantuvieran en secreto. La violencia de género impone a las mujeres el silencio sobre su dolor. Sus sufrimientos se mantienen en secreto y se mantienen en la casa, y la religión tiene una participación importante en esto, generando la desmovilización de la indignación contra la producción del sufrimiento impuesto contra las mujeres. Este artículo tiene como objetivo abordar el silenciamiento de las mujeres en situaciones de violencia como un mecanismo para obstaculizar el compromiso social con sus vidas, y toma el caso específico de la niña de diez años que fue violada y se quedó embarazada por su tío en Espírito Santo para guiar esta discusión.

Palabras-clave: Violencia contra las mujeres; Silenciamiento; Sufrimiento; Religión.

As mulheres não estão sozinhas neste silêncio profundo. Ele envolve o continente perdido das vidas tragadas pelo esquecimento em que se aniquila a massa da humanidade. Mas ele pesa mais fortemente sobre elas, em razão da desigualdade dos sexos, esta "valência diferencial" que estrutura o passado das sociedades. (Michelle PERROT, 2005, p. 11)

\section{Contar a violência}

Ao escrever sobre o silêncio da História acerca das mulheres, Michelle Perrot traz à tona o debate sobre a eleição do que e de quem é narrável e não narrável e ressalta a indiferença ainda reinante em relação à história das mulheres. Ela problematiza o pressuposto que orienta a escrita da história ocidental que universaliza a agência masculina apagando sistematicamente a agência das mulheres, relegando-as a "um oceano de silêncio" (Michelle PERROT, 2005, p. 9), como se "fora do tempo, ou ao menos fora do acontecimento" (2005, p. 9) e, por que não, fora da humanidade. Esse contar 
Religião e silenciamento do sofrimento: 339 reflexões sobre morte e vida de mulheres em situação de violência

histórico é seletivo, e se é verdade que ele não exclui somente as mulheres, essa ausência é flagrante na historiografia.

A predominância de registros sobre os homens contribui para a sedimentação de uma memória que está habituada a essa presença masculina açambarcante, e que contamina a narrativa histórica, mantendo-a acomodada à ausência das mulheres, perpetuando o seu "esquecimento". A inenarrabilidade das mulheres se impõe com a naturalidade necessária à permanência da dominância patriarcal. Silenciar sobre as mulheres, ignorando sua agência histórica e silenciar as mulheres, negando-lhes o direito de se contarem, configura uma política de dominação, mas essa dominação não está somente no silêncio e no silenciamento. A visibilidade também é normalizada. O contar-se a si mesma está delimitado pela norma. Somos sujeitos constituídos dentro de um regime de verdade, e na medida em que usamos a norma, somos usadas por ela (Judith BUTLER, 2015, p. 51). Porém, contar-se a si é uma "técnica de si", um "apropriar-se de si" que, segundo Michel Foucault (1990), explicita os mecanismos de assujeitamento e revela o sujeito e suas potencialidades, um sujeito menos permeável às regulações que o envolvem.

Os relatos de mulheres vítimas de violência sexual e de gênero podem ser entendidos nessa perspectiva. Eles têm se multiplicado tanto por meio da denúncia aos mecanismos formais do Estado e da "tradução" dessas violências pela grande mídia, quanto pelo compartilhamento dessas experiências em redes sociais, grupos religiosos e outros espaços. Contar a violência sofrida implica romper o silêncio que envolve essa experiência e, portanto, a solidão que amedronta e imobiliza. O segredo acerca da violência contra as mulheres a tem perpetuado. Dizê-la é confrontar os regimes de verdade. $\mathrm{Na}$ interpelação questionam-se os esquemas de inteligibilidade.

Algumas pesquisas (OROZCO, Yury, 2019; OSHIRO, Claudia Poleti, 2017; SOUZA, Sandra Duarte e OSHIRO, Cláudia Poleti, 2018; VILHENA, Valéria, 2009) e o próprio acompanhamento de mulheres em situação de violência têm revelado que em determinados espaços religiosos ainda persiste a recomendação do silêncio e da sujeição das mulheres à violência. No Brasil essas pesquisas tratam especialmente de mulheres de tradição cristã. Há pelo menos duas percepções acerca da forma como diferentes lideranças religiosas abordam o problema da violência contra as mulheres: algumas estimulam a denúncia, dão suporte para a vítima, promovem rodas de conversa para "dizer a violência", produzem material norteador para o enfrentamento da violência e orientam a comunidade dentre outras iniciativas, enquanto outras 
se negam a enfrentar o problema, minimizam a responsabilidade do agressor, atribuem a violência à ação do demônio, desestimulam a denúncia e orientam a mulher a se calar sobre o ocorrido.

Essa segunda abordagem que pretende o assujeitamento das mulheres ainda predomina nos mais diversos segmentos religiosos. Ela prescreve às mulheres a aceitação dócil e "discreta" da violência. A liderança religiosa, não raras vezes, atua como agente normalizador da submissão, explicando a violência como destino natural das mulheres. Ela tenta manter o relato de suas experiências de sofrimento na sala pastoral, aconselhando a resignação, contendo a indignação e evitando a sua publicização. Quando as mulheres publicizam a violência, o pastor/padre e outros membros da comunidade religiosa tentam diminuir a gravidade da ação do agressor ou então questionam a própria mulher, buscando subtrair a legitimidade do relato e, portanto, da relatante.

\section{Uma algazarra silenciadora}

Os dados relativos à morte e adoecimento de mulheres no Brasil e no mundo diretamente relacionados à violência de gênero atestam que há um imenso contingente de mulheres que, por força dessa violência, têm suas vidas abreviadas. Algumas, pela ação letal dos companheiros feminicidas, outras, por se cuidarem menos por causa dos danos psíquicos provocados pela violência doméstica, pela violência no trabalho, na escola e na própria religião. Mulheres que experimentam a violência fazem, por exemplo, menos exames preventivos, inclusive exames ginecológicos, estando mais propensas a desenvolver neoplasias do colo do útero e das mamas (LEITE, Franciele et. al, 2018; GANDHI, Sheetal et. al, 2010). Elas estão também mais propensas ao desenvolvimento de depressão e, especialmente no caso de estupro, a tentativas suicidas (SILVA, Ângela, 2019). O fato é que a morte de mulheres em consequência da violência de gênero nos faz pensar nessa antecipação da morte e nos mecanismos que compactuam para o apressamento do fim da vida das mulheres.

Inventariar as muitas violências contra as mulheres é trabalho dificílimo, uma vez que elas se apresentam de múltiplas formas, em distintos ambientes, impetradas por incontáveis sujeitos e instituições. É ainda mais difícil porque a violência reguladora é normalmente travestida de cuidado.

O caso da menina pobre, negra, violentada e engravidada pelo tio e que foi objeto da fúria de algumas pessoas que afirmavam fazer isso em nome 
de Deus, é emblemático. A menina de dez anos, que aqui vamos chamar de Tamar ${ }^{1}$, acompanhando a memória trazida dessa personagem bíblica pelo "Manifesto de Cristãs" sobre esse caso ${ }^{2}$, foi sistematicamente violentada pelo tio desde os seis anos de idade. Para o tio, Tamar era apenas um corpinho disponível para o seu prazer sexual. Sua vida não importava. O tempo passava e a menina sofria...

Aos dez anos a violência resultou em gravidez naquele corpo miúdo e em formação. Gravidez produto da violência do tio, aquele membro da família que fomos ensinadas a acreditar ser um segundo pai que cuida e protege. Nossas representações de pai, tio, irmão, namorado, marido parecem se distanciar dolorosamente da experiência violenta de inumeráveis mulheres com esses familiares. O tempo passava e a menina sofria...

A violência continuou, agora, pela burocrática necessidade de pedido de autorização judicial para a interrupção da gravidez de risco de uma menina de dez anos vítima de crime de estupro. A Justiça que, para cuidar, regula quem está ou não autorizada a abortar. O tempo passava e a menina sofria...

$\mathrm{Na}$ sequência foi a vez da equipe médica do Hospital Universitário Cassiano Antônio Moraes, de Vitória-ES, que se negou a realizar o procedimento do aborto, mesmo havendo decisão judicial que amparava a prática, alegando que a gestação se encontrava em estágio avançado e ultrapassava o período previsto por lei. Essa instituição que se apresenta como instituição de cuidados, não quis cuidar de Tamar. O tempo passava e a menina sofria...

Mais uma vez a vida de Tamar não importava. A menina miudinha do interior do Espírito Santo continuou sua peregrinação em busca de cuidados e teve que se deslocar de sua cidade numa migração forçada para ser atendida em Recife. O tempo passava e a menina sofria...

Mas não parou por aí. Outros agentes entraram na disputa pela regulação daquele corpo miúdo. Dessa vez políticos e religiosos, ou políticos religiosos, duas instituições cuja legitimidade da existência passa pelo discurso do cuidado. O que vimos, porém, foram cenas de violência, de violação de direitos em que tais agentes buscavam basicamente tirar proveito político

Tamar é uma personagem bíblica que foi violentada pelo seu irmão Amnon (ver: II Samuel $13,1-22)$.

2 Manifesto de cristãs sobre o caso do Espírito Santo. Disponível em: https://cebi.org.br/ noticias/manifesto-de-cristas-sobre-o-caso-do-espirito-santo/ Acesso em: 27 ago. 2020. O manifesto foi assinado por leigas, diáconas, catequistas, ministras, reverendas, pastoras, religiosas, teólogas e bispas. 
e religioso da situação. O rompimento do silêncio sobre a violência se deu somente quando o corpo da criança manifestou o que não cabia nele.

Depois de anos de silêncio a menina podia falar, mas o regime de vigilância da ordem patriarcal fez barulho para não deixá-la falar. Para apagar a incômoda evidência corporal da violência, tentaram gritar mais alto do que o corpo de Tamar. Violentaram o sigilo da identidade da menina, invadiram a sua casa e tentaram invadir, mais uma vez, o seu corpo. Um grupo de pessoas autodeclaradas católicas lideradas por um candidato à vereança de São Mateus-ES, Pedro Teodoro, se postou na casa da menina e pressionou a avó para não permitir o aborto, utilizando argumentos religiosos. O grupo permaneceu por algum tempo no quintal rezando enquanto os familiares da criança rebatiam os seus argumentos e pediam para que se retirassem. $\mathrm{O}$ tempo passava e a menina sofria...

Outra cena barulhenta visando calar a voz da menina ocorreu no hospital onde o procedimento foi realizado. A imagem dos deputados estaduais Clarissa Tércio (PSC) e Joel da Harpa (PP), ambos da bancada evangélica, fazendo uma live durante o tumulto em frente ao hospital especializado em casos de alto risco, expressa a sordidez do movimento. A eles se juntaram também manifestantes autodeclarados católicos das comunidades Porta Fidei e Diante do Altar dentre outras. O grupo enraivecido, autoproclamado santo, fez muito barulho em frente ao hospital e nas redes sociais. Autoproclamando-se defensor da família, o grupo impediu a entrada de pessoas no hospital, tentou romper a barreira policial para entrar à força naquela instituição e não teve dúvidas em identificar a "criminosa": a pequena estuprada Tamar. O grito "assassina" ecoava nos corredores do hospital. Não se sabe se Tamar escutou, mas o tempo passava e a menina sofria...

A algazarra ensurdecedora se pretendia silenciadora. Silenciadora da menina, da sua avó, das e dos profissionais de saúde que as atenderam. Mais ainda, pretendia provocar o esquecimento do sofrimento de Tamar e de todas as mulheres vítimas da violência sexual e de tantas outras violências. Os sofrimentos das mulheres estão numa escala inferior de importância. Eles foram historicamente ignorados, mesmo que, como lembra enfaticamente Julieta Paredes, as mulheres sejam "a metade de cada povo" (PAREDES, Julieta, 2010, p. 39).

O caso de Tamar sintetiza as tensões que envolvem o tema do aborto no Brasil. No âmbito político, essa discussão está nas mãos dos homens. Em levantamento realizado acerca do debate sobre o aborto na Câmara dos Deputados entre 1991 e 2014, Luis Miguel, Flávia Biroli e Rayani Mariano 
constataram que em virtude da baixa representatividade de mulheres no parlamento, mesmo havendo interesse delas no tema, "a questão do aborto é o foco central de $61,7 \%$ dos discursos deles, mas apenas $49,2 \%$ dos discursos delas" (2016, p. 136). Os argumentos e posicionamentos são predominantemente contrários à interrupção da gravidez e à criação ou mesmo manutenção de serviços de atendimento a mulheres que passam pela difícil experiência do aborto. Em 1997, por exemplo, alguns parlamentares conseguiram impedir o encaminhamento do PL 20/1991 ao Senado. Esse projeto de lei visava garantir atendimento às mulheres na rede pública em casos de aborto previstos por lei. Diante da obstaculização desse direito provocada pelo Legislativo, os movimentos feministas pressionaram o Ministério da Saúde, que regulamentou o atendimento por meio da publicação de norma técnica. Nos anos seguintes testemunhamos a criação de diferentes frentes parlamentares que tomaram o discurso contra o aborto e por sua criminalização como bandeira. Esse é o caso da Frente Parlamentar Evangélica, a Frente Parlamentar Contra a Legalização do Aborto, a Frente Parlamentar da Família e Apoio à Vida, e a Frente Parlamentar Mista em Defesa da Vida - Contra o Aborto (MIGUEL, Luis Felipe; BIROLI, Flávia; MARIANO, Rayani, 2016, p.139). A ênfase antiaborto marcou os discursos das campanhas eleitorais de 2010, 2014 e 2018, em que importantes atores religiosos com discursos contrários aos direitos reprodutivos e sexuais, negociaram com políticos diversos o voto do eleitorado católico e evangélico conservador. Isso pode ser percebido na indiferença proposital ao tratamento do aborto como uma questão de direito, restringindo o debate ao campo da moral, com explícito discurso moralista religioso.

O impacto disso sobre as vidas das mulheres se verifica na não proposição de políticas públicas voltadas para o atendimento e acompanhamento daquelas que passaram pela experiência do aborto, no não investimento nos serviços existentes que foram conquistados por força dos movimentos de mulheres, na criação de mecanismos legais visando dificultar e mesmo obstruir o acesso a tais serviços e nas constantes tentativas de criminalizar o aborto em quaisquer circunstâncias. A negligência do Estado é flagrante, e os dados oficiais relativos à ocorrência de aborto no Brasil, mesmo que imprecisos ${ }^{3}$, revelam a política de Estado na gestão da morte das mulheres. Essa política aposta no silêncio das mulheres.

\footnotetext{
3 A base de dados do sistema nacional de saúde registra apenas os óbitos e internações por aborto atendidos no sistema público de saúde.

4 A esse respeito verifique o conceito de necropolítica, de Achile Mbembe (2018).
} 
A criminalização do aborto gera temor nas mulheres que, não raras vezes, silenciam sobre o ocorrido, realizando o procedimento de forma clandestina e amadora, colocando suas vidas em risco. Mas o silêncio também é alimentado pela severidade do tratamento familiar e religioso sobre o tema. Nos relatos de mulheres que engravidaram por força do abuso sexual e já abortaram, é recorrente a menção à família e à religião como instituições que lhes impõem o silêncio sobre os abusos sofridos. Esse silêncio se impõe pelo medo de falar e, assim, termina prolongando os abusos e dificultando o registro e tratamento apropriado de milhares de casos que ocorrem às escondidas, sob o medo da punição. A peregrinação de Tamar explicita a lógica de morte no tratamento dispensado a mulheres que sofrem abuso sexual e que abortam, em especial, mulheres negras e pobres, vidas que pouco ou nada importam (BUTLER, Judith, 2020) e sobre as quais pesa o silêncio imposto por distintas instituições.

\section{Sobre silêncio e precariedade}

A violência de gênero impõe às mulheres o silêncio sobre as suas dores. Seus sofrimentos são mantidos em segredo, o que significa dizer que a invisibilidade da violência gera a falsa sensação da sua inexistência e, portanto, os violentadores não são responsabilizados porque não denunciados; limitamse as proposições de políticas públicas para o enfrentamento da violência contra as mulheres; reforça-se o discurso-crença da culpa da vítima, gerando mais sofrimento, doenças e morte de mulheres. Enfim, a violência contra as mulheres se faz sentir na pactuação da cultura do silêncio e na negação da própria existência da violência (SOUZA, Sandra Duarte e OSHIRO, Cláudia Poleti, 2018, p. 214). O mundo patriarcal escondeu o sofrimento das mulheres. A invenção e hierarquização do público e do privado e a consequente associação dos homens ao público e das mulheres ao privado, também serviu a esse propósito. Os sofrimentos das mulheres foram trancados na casa:

Abusos ocultados sob o argumento da intocabilidade da casa e da família, normalizaram a opressão e repressão das mulheres. A evocação da autoridade do pai ou do homem da casa legitimou estupros, privação de liberdade, exploração econômica, negação do direito ao estudo, espancamentos e inumeráveis (porque não contáveis) homicídios. Dentro da casa tudo era possível. (SOUZA, Sandra Duarte, 2014, p. 11-12) 
Só muito recentemente as mulheres têm tornado públicas as suas dores. Como bem lembra Débora Diniz na live "Sofrimentos das Mulheres", em que promoveu um diálogo com as teólogas Ivone Gebara e Lusmarina Campos Garcia ${ }^{5}$, Tamar foi engravidada em tempos de pandemia. Sim, ela já era violentada há anos, mas o fato da gravidez vir durante a pandemia, explicita ainda mais a perversidade da situação. O lugar sistematicamente afirmado como o mais seguro para as mulheres, a casa, é o lugar dos abusos, da violência. Quando o corpo ferido sai da casa e se mostra, ele publiciza uma violência entendida como segredo de família. Ele escancara a precariedade da vida das mulheres, esse modo de existência em risco permanente.

Os corpos feridos das mulheres incomodam. Melhor não vê-los, pois assim podemos continuar ignorando a sua humanidade e dessa forma, escapar àquilo que nos vincula eticamente. $\mathrm{O}$ conhecido e exaustivamente repetido "em briga de marido e mulher não se mete a colher", serve bem a esse propósito de manter o sofrimento das mulheres longe dos olhos da sociedade, e assim, na ignorância, nos sentimos menos vinculados a elas. Aliás, a pergunta pelo que nos vincula eticamente à alteridade nos é colocada, dentre outros pesquisadores e pesquisadoras, por Judith Butler. Para ela, num contexto capitalista, racista e patriarcal, as vidas humanas possuem um valor desigual, e nessa lógica, algumas vidas podem ser descartadas como não-vidas. Butler chama a atenção para a produção sociopolítica da precariedade, que expõe determinadas populações ao risco do sofrimento e da morte. Segundo ela, "a precariedade designa a situação politicamente induzida, na qual determinadas populações sofrem as consequências da deterioração das redes de apoio sociais e econômicas mais do que outras, e ficam diferencialmente expostas ao dano, à violência e à morte" (BUTLER, Judith, 2018, p. 40).

Se é verdade que todas e todos compartilhamos a condição de vulnerabilidade, algumas e alguns de nós importam menos, marcadas/os que estamos pela desigualdade de gênero, raça e classe. Se na métrica social há vidas que importam menos ou que não importam, vidas que não merecem ser choradas porque não-vidas, como gerar um senso de solidariedade, um vínculo com elas? Como haver esse senso de solidariedade diante de estruturas que expõem algumas pessoas mais à morte do que outras, que justificam a destruição arbitrária de algumas vidas, de populações inteiras?

Disponível em: https://www.youtube.com/watch?v=ILfiyqZdA9E Acesso em: 28 ago. 2020. 
Já nos acomodamos ao fato de sermos um dos países que mais mata mulheres. Isso para não falar da população LGBTQI+. Assumimos o sofrimento e a morte das mulheres como parte da dinâmica da vida. Mas não seria o caso de observá-los como parte de um projeto seletivo que define com antecedência quem deve viver e quem deve morrer? Como afirma Butler, em entrevista a Francis Wade, "qualquer política ou instituição que crie taxas de mortalidade aumentadas para um grupo está envolvida em uma forma de negociação de mortes" (WADE, Francis, 2020). A ausência ou precarização de infraestruturas e de instituições sociais e políticas de apoio a mulheres atesta essa política letal. A morte anual de milhares de mulheres por abortos inseguros, e um Estado que se nega a criar e manter serviços de abortamento legal e que, além de tudo, criminaliza aquelas que abortam em situações não admitidas pela lei e que quer tornar crime aquelas situações que hoje são legais, evidenciam uma política de morte que tem as mulheres como alvo. As empreitadas de políticos religiosos nas diversas instâncias legislativas do país que se esforçam por obstaculizar e mesmo anular leis relativas aos direitos reprodutivos das mulheres também compõem essa ação articulada de efeito devastador sobre suas vidas. Um Estado que fecha serviços de atendimento a mulheres em situação de violência doméstica em um país em que $70 \%$ da violência cometida contra mulheres, inclusive abuso sexual, ocorre dentro da casa, por ação de maridos, namorados, filhos, irmãos, pais e avós, e uma religião que aconselha essas mulheres a permanecerem em relações violentas à espera da transformação do seu agressor, explicita o quão pouco importam as vidas das mulheres. Considerando os marcadores sociais de gênero, raça e classe, a letalidade desse sistema é ainda mais explícita. Quando as mulheres são pobres, pretas, lésbicas, trans, importam menos ainda. No Brasil, conforme indicam Bruno Cardoso, Fernanda Vieira e Valéria Saraceni (2020), a partir de levantamento dos dados oficiais sobre aborto no país, a maioria das mulheres que morrem em decorrência de aborto são negras ou indígenas, pobres, com baixa escolaridade e têm idade abaixo de 14 anos ou superior a 40 anos. Não é apenas uma coincidência que Tamar seja menina, pobre e preta. Ela compõe o contingente de sujeitos/corpos ignorados como vidas que importam.

Ainda carecemos de uma discussão mais ampla da violência contra as mulheres entendida como "negligência sistêmica". Todas/os sabemos, mas quantas e quantos de nós lamentamos? Todos os dias enterram-se mulheres vítimas da violência, não por acaso, majoritariamente negras, mas isso 
parece não causar estranheza. Em 2019, destacando aqui apenas os casos registrados como feminicídio, foram mais de 1.300 assassinatos de mulheres pelo simples fato de serem mulheres. São $7 \%$ a mais que os registros de 2018. Se contabilizarmos outros homicídios de mulheres não classificados como feminicídio, o número ultrapassa 3.700 assassinatos (NEV - Núcleo de Estudos de Violência da USP) ${ }^{6}$. Por que essas mortes não provocam o choro social? Por que não provocam o luto público? Porque nem todas as vidas são importantes. Se o fossem, elas seriam igualmente cuidadas e lamentadas.

A construção de uma teia de cuidado das mulheres parece ser um importante caminho no enfrentamento às violências experimentadas, e aí temos um ponto fundamental: a percepção de que esse cuidado depende do efetivo comprometimento com a vida das mulheres. Como afirma Butler,

Quando tentamos entender, em termos concretos, o que significa nos comprometermos com a preservação da vida do outro, somos invariavelmente confrontados com as condições corporais da vida e, portanto, com um compromisso não apenas com a persistência corpórea do outro, mas com todas as condições ambientais que tornam a vida possível de ser vivida. (BUTLER, Judith, 2018, p. 80)

Há, porém, um processo de dificultação do estabelecimento desse compromisso, implicando na não identificação com o sofrimento do outro e da outra e, portanto, nos isentando da responsabilidade de preservar a sua vida e as condições que a viabilizam. Em outras palavras, há um processo de obstaculização do encontro ético. Ivone Gebara, ao se referir à violência contra as mulheres, afirma que "nossos sofrimentos foram mantidos em segredo" e a religião tem importante participação nisso. Ao que parece, isso envolve uma intencional desmobilização da indignação contra a produção do sofrimento impetrado contra as mulheres.

Depois de tantos anos acompanhando mulheres evangélicas em situação de violência e desenvolvendo rodas de conversa em comunidades religiosas, não temos como não nos referir aos inúmeros relatos de mulheres que foram aconselhadas pastoralmente a aguentarem caladas e em oração, pois Deus

${ }^{6}$ Levantamento realizado pelo NEV em parceria com o Fórum Brasileiro de Segurança Pública e o G1 Disponível em: https://nev.prp.usp.br/homicidios/mesmo-com-quedarecorde-de-mortes-de-mulheres-brasil-tem-alta-no-numero-de-feminicidios-em-2019/ Acesso em: 2 de jul. 2020.

7 Live "Sofrimentos das Mulheres". Disponível em: https://www.youtube.com/ watch?v=lLfiyqZdA9E Acesso em: 28 ago. 2020. 
"libertaria" seus maridos e a família seria feliz. Era importante defender essa instituição que deve ser preservada a qualquer custo: o casamento. Era importante não "expor" os maridos e, mais importante ainda, se sujeitar ao relacionamento violento em favor dos filhos. Seu sofrimento era coisa menor. O sem sentido da violência experimentada era significado em termos de obediência a uma teologia que lhes poderia ser fatal. O mesmo em relação às mulheres que abortam. Elas são instadas a se calar, a ter vergonha do que aconteceu. Vivem a mortal solidão de uma dor que não pode nem ao menos ser ritualizada, porque condenada. Manter as mulheres na solidão do seu sofrimento é conveniente a um sistema patriarcal que se reproduz apostando em políticas de morte. E assim elas vão morrendo...

\section{Uma oração coletiva pela vida das mulheres}

A afirmação insistente do segredo sobre a violência experimentada faz parecer que essa é uma experiência solitária, gerando sentimento de impotência, de culpa e de consequente aceitação dessa situação pelas mulheres. É por esse motivo que grupos que militam pelo enfrentamento à violência contra as mulheres reivindicam a publicização dessas experiências ${ }^{8}$. Dizê-las é encontrar uma comunidade de iguais e se fortalecer.

Esse empoderamento pelo contar também pode ocorrer no ambiente religioso. Foi na percepção de que as rodas de conversa sobre enfrentamento à violência contra mulheres, ocorridas em algumas igrejas, não eram apenas nem principalmente encontros de capacitação, que nos demos conta do lugar restaurador desses encontros. É ali que a solidão se desfaz. Elas se contam e se encontram nesse contar. Percebem que não apenas outras já passaram pelo que elas passaram, mas principalmente que elas se indignam juntas e reagem juntas ao sofrimento que já não é mais individual e já não é mais escravo do silêncio.

Em uma roda de conversa sobre a cultura do estupro organizada por Koinonia em 2016, uma das participantes do encontro se apercebeu de sua condição de mulher violentada. Sua percepção dessa situação, de que era sistematicamente violentada pelo seu marido, impactou fortemente a sua vida. Meses depois a entrevistamos e, ao concluir um texto sobre o tema,

\footnotetext{
8 A esse respeito, consultar o Instagram da rede colaborativa "Mete a colher", que apoia mulheres a romperem com relacionamentos abusivos. Disponível em: https://www. instagram.com/appmeteacolher/. Ver também \#VizinhaVocêNãoEstáSozinha. Disponível em: https://www.instagram.com/explore/tags/vizinhavoc $\% \mathrm{C} 3 \% \mathrm{AAn} \% \mathrm{C} 3 \% \mathrm{~A} 3$ oest $\% \mathrm{C} 3$ $\%$ A1sozinha/
} 
Religião e silenciamento do sofrimento: 349 reflexões sobre morte e vida de mulheres em situação de violência

repassamos a ela para sua avaliação e autorização para a publicação ou não do material. Depois de ler o material, ela disse: "por que a gente não conversa com outras mulheres sobre isso?! Tem que fazer mais daquela reunião.” Ela fez. De lá para cá ela começou a reunir mulheres de sua comunidade religiosa pentecostal, para orarem, cantarem, lerem a Bíblia e falarem sobre si. Temas como sexualidade, direitos reprodutivos e violência contra as mulheres compõem a pauta dos encontros. Ali, essas mulheres falam de Deus, fazem oração com imposição de mãos, falam dos seus sofrimentos, desengavetam abortos, lembram de abusos perpetrados por seus conhecidos na infância, falam da violência de seus companheiros e filhos e constroem fortes vínculos umas com as outras. Cada uma falando de si e falando de todas, vivendo uma intensa experiência coletiva de cura. Algumas dessas mulheres vão menos à igreja do que a esses encontros.

Publicizar o sofrimento, mesmo que de forma restrita, tem ação sanadora para essas mulheres. Isso é o que realmente poderíamos chamar de encontros de cura e libertação, para usarmos uma expressão comum ao campo religioso pentecostal. O sem sentido do sofrimento dá lugar ao sentido de uma nova vida. O rompimento do pacto de silêncio publiciza o sofrimento que perdurou por anos em suas vidas e é aí que a morte se faz vida.

Para finalizar, voltamos a Tamar. Naquela noite no hospital, Tamar não podia falar. Apesar da maior ênfase da mídia ter sido nas imagens e gritos acusatórios protagonizados por alguns raivosos manifestantes contra o aborto, havia ali dezenas de mulheres se manifestando com seus incômodos corpos eretos arrimados em frente ao hospital, tomando a rua. Elas foram até lá contar o que esses furiosos religiosos não queriam que se contasse. Naquilo que podemos caracterizar como uma "oração coletiva", elas falaram e repetiram:

"Essa criança, depois de ser violentada, engravidou fruto desse estupro. E os fundamentalistas estão aqui para dizer que a vida dela não importa, para colocar a vida de uma menina de 10 anos em risco. Nós estamos aqui (...) para dizer que as nossas vidas importam, que a vida dessa menina estuprada importa para toda a sociedade. O aborto legal é um direito. Não vamos abrir mão disso, não vamos abrir mão de uma menina de dez anos. Gravidez forçada é tortura. Gravidez aos dez anos é morte. É por isso que a gente vai dizer e vai repetir: Aborto legal, seguro e gratuito para não morrer. Pela vida das meninas e das mulheres"!?

9 Disponível em: https://www.correio24horas.com.br/noticia/nid/apos-confusao-mulheresvao-a-hospital-para-apoiar-menina-estuprada/ Acesso em 1 de set. 2020. 
Essa cena é poderosa. Quando uma fala, todas repetem, numa voz que ecoa. Corpos em aliança demandando "vidas mais vivíveis" (BUTLER, Judith, 2018, p. 31).

Finalizo aqui com uma palavra da Débora Diniz, que no exílio forçado por ameaça de morte continua a falar sobre a vida das mulheres. Tratando desse tempo de pandemia e do sofrimento que ela tem causado, ela afirma que ele

nos deixa uma ferida ética, mas essa ferida ética pode ser criativa. O sofrimento não é só desamparo, o desamparo de uma falta de sentido. Ele é uma convocação para uma criação de sentido no comum. As nossas construções de um individuo imunizado para o comum estão fracassando, e as nossas respostas têm que ser o retorno ao comum". ${ }^{10}$

\section{Referências}

BUTLER, Judith. 'De quem são as vidas consideradas choráveis em nosso mundo público?'. El País, 12 de julho de 2020. Disponível em: https://brasil.elpais.com/babelia/2020-07-10/ judith-butler-de-quem-sao-as-vidas-consideradas-choraveis-em-nosso-mundo-publico.html Acesso em: 10 ago. 2020.

BUTLER, Judith. Relatar a si mesmo. Crítica da violência ética. Belo Horizonte: Autêntica, 2015.

BUTLER, Judith. Corpos em aliança e a política das ruas: notas para uma teoria performativa de assembleia. Rio de Janeiro, Civilização Brasileira, 2018.

FOUCAULT, Michel. Tecnologias del yo - Y otros textos afines. Barcelona: Paidós Ibérica, 1990.

GANDHI, S., ROVI S., VEJA, Marielos, JOHNSON, M. S., FERRANTE, J., CHEN, P. Intimate partner violence and cancer screening among urban minority women. The Journal of the American Board of Family Medicine, Lexington. May/Jun. 2010; 23(3):343-53.

LEITE, Franciele M. Costa; AMORIM, Maria Helena C.; GIGANTE, Denise P. Implicações das violências contra as mulheres sobre a não realização do exame citopatológico. Revista Saúde Pública, 2018; 52:89, p. 1-10. Disponível em: http://www.revistas.usp.br/rsp/article/ view/151816/148749 Acesso em: 7 abril 2020.

MBEMBE, Achille. Necropolítica: biopoder, soberania, estado de exceção, política da morte. São Paulo: N-1 edições, 2018.

CARDOSO, Bruno B., VIEIRA, Fernanda M. S. B., SARACENI, Valeria. Aborto no Brasil: o que dizem os dados oficiais? Cad. Saúde Pública, 36, supl. 1, 2020. Disponível em: http:// cadernos.ensp.fiocruz.br/csp/artigo/975/aborto-no-brasil-o-que-dizem-os-dados-oficiais

10 Disponível em: Disponível em: https://www.youtube.com/watch?v=lLfiyqZdA9E Acesso em: 28 ago. 2020. 
reflexões sobre morte e vida de mulheres em situação de violência

Acesso em: 03 dez. 2020.

MIGUEL, Luis Felipe; BIROLI, Flávia; \& MARIANO, Rayani. O Debate Sobre o Aborto na Câmara dos Deputados, de 1990 a 2014. p. 128 - 154. In: BIROLI, Flávia; \& MIGUEL, Luis Felipe (orgs.). Aborto e Democracia. São Paulo: Alameda, 2016.

OROZCO, Yury Puello (org.). Religiões em diálogo: violência contra as mulheres. São Paulo: Católicas pelo Direito de Decidir, 2009.

OSHIRO, Claudia Maria Poleti. Violência de Gênero e Religião: uma análise da influência do Cristianismo em relações familiares violentas a partir de mulheres acolhidas nas Casas Abrigo Regional Grande ABC e de homens autores de violência doméstica. 2017. Dissertação (Ciências da Religião) - Universidade Metodista de São Paulo, São Bernardo do Campo.

PAREDES, Julieta. Hilando Fino. Desde el feminismo comunitário. La Paz. Comunidad Mujeres Creando Comunidad, 2010.

PERROT, Michelle. As mulheres ou os silêncios da História. Bauru: Edusc, 2005.

SILVA, Ângela Pires. Estupro e tentativa de suicídio. O impacto social no cotidiano da mulher. In: PEREIRA, Eliane Regina (org.). Saúde mental: um campo em construção. Ponta Grossa, Atena, 2019, p. 116-126.

SOUZA, Sandra Duarte de; OSHIRO, Cláudia M. Poleti. Mulheres evangélicas e violência doméstica: o que o poder público e a igreja têm a ver com isso? Caminhos, v. 16, n. 2, 2018, p. 203-2019. Disponível em: http://seer.pucgoias.edu.br/index.php/caminhos/article/ view/6730/3786 Acesso em: 02 mar. 2020.

SOUZA, Sandra Duarte de. 'Eu não sou mulher': violência doméstica e ética cristã. Revista Caminhando, v. 19, n. 2, p. 7-17, jul./dez. 2014.

VILHENA, Valéria Cristina. Pela voz das mulheres: uma análise da violência doméstica entre mulheres evangélicas atendidas no Núcleo de Defesa e Convivência da Mulher - Casa Sofia. Dissertação (Mestrado em Ciências da Religião), Universidade Metodista de São Paulo, 2009.

WADE, Francis. Judith Butler lança sua aposta na não violência. The Nation, 2020. Disponível em: https://outraspalavras.net/outrasmidias/judith-butler-negligencia-do-estado-e-violenciaendemica/ Acesso em: 27 maio 2020.

Submetido em: 29-11-2020

Aceito em: 9-12-2020 